\title{
MSPD as sample preparation method for determination of selected pesticide residues in apples
}

\author{
Andrea Purdešováa ${ }^{a}$ Milena Dömötorováb \\ ${ }^{a}$ Institute of Analytical Chemistry, Faculty of Chemical and Food Technology, STU, \\ Radlinského 9, 81237 Bratislava, Slovakia \\ ${ }^{b}$ Public Health Officer of the Slovak Republic, \\ Trnavská cesta 52, P.O.BOX 45, 82645 Bratislava 29, Slovak Republic \\ andrea.purdesova@stuba.sk
}

\begin{abstract}
A method for extraction and fast gas chromatographic (GC) determination of twenty pesticide residues of different volatility and polarity at ultratrace concentration level in apples is presented. Apples as representatives of non-fatty food were chosen as a matrix; they are also a common raw material for baby food production. Under fast GC conditions employing a mass spectrometric detector (MSD), several parameters of the MSPD procedure were optimised. Samples were homogenised with sorbent Florisil, pesticides were eluted with the optimised volume of etylacetate. After solvent evaporation to dryness, reconstitution of the rest to toluene follow and the final extract was injected. Recoveries obtained at three selected concentration levels were determined. The optimised procedure led to recoveries $\geq 90 \%$ for the majority of the studied pesticides and the limits of quantification (LOQs) $<5 \mu \mathrm{g} \cdot \mathrm{kg}^{-1}$.

Repeatability of gas chromatography-mass spectrometry (GC-MS) measurements of the matrix matched standards, expressed as the relative standard deviation (RSD [\%]), was in most cases acceptable for ultratrace concentration levels of pesticide residues.
\end{abstract}

Keywords: Fast GC, GC-MS, MSPD

\section{Introduction}

Pesticide is a general term that includes a variety of chemical and biological products used to kill or control living organisms such as rodents, insects, fungi in plants (http://www.pesticides. gov.uk/environment.asp?id=1523). Adverse effects of pesticide residues remaining in food after their application to food crops on human health are generally known: acute neurologic toxicity, chronic neurodevelopment impairment, possible dysfunction of the immune, reproductive and/or endocrine systems, cancer and many others.

Residues in fruit and vegetables, cereals and foodstuffs of animal origin (and processed baby food) are controlled through a system of statutory Maximum Residue Limits (MRLs). Lower values of MRLs are set for baby food - EC specified the MRL of $0.010 \mathrm{mg} / \mathrm{kg}$ (Commission Directive 2003/13/EC 2003). Scientifically valid analysis methods at low concentration levels, currently still often very close to the limits of quantification (LOQs), are essential for surveillance/ compliance programs established with the terminal goal to minimise the hazards and the health risks and to achieve more sustainable application of pesticides (Matisová, 2003; Kirchner, 2004; Kirchner, 2005). The most suitable for the determination of pesticide residues content in food samples are chroma- tographic methods with various sample preparation methods. Trends in GC are the ever increasing need for positive identification and more flexible systems allowing the analysis of a wide variety of samples in one system. These trends clearly result in the need for mass spectrometric detection.

The most common raw material for baby food production in Slovakia is apple. The matrix of apple is complex; therefore, the sample preparation represents one of the most critical parts of the analysis (Hercegová, 2005; Dömötorová, 2005; Hercegová, 2006).

In general, sample preparation methods for nonfatty foods include liquid extractions followed by a clean-up method, e.g. solid phase extraction (SPE) (Schenck, 2002; Anastassiades, 2003), or several alternative methods developed with the goal of solvent consumption reduction. The trend is to reduce solvent consumption and manual labour. In 2003, Anastassiades et al. (Anastassiades, 2003) introduced a quick, easy, cheap, effective, rugged, and safe (QuEChERS) method for the analysis of pesticide residues in fruit and vegetables. Popular pre-treatment methods for multiresidue pesticide analysis include microwave-assisted extraction (MAE) (Fernandes, 2011), supercritical fluid extraction (SFE), membrane extraction (Ferrer, 2011) and matrix solid phase dispersion (MSPD). 
Most applications of MSPD for pesticides analysis in food employ a reversed-phase material, particularly C18 and C8 (Navarro, 2002; Kristenson, 2001; Blasco, 2002) and sorbent Florisil (Viana, 1996).

The sample preparation procedure should include chromatographic analysis and detection mainly in LOQs and selectivity. Capillary GC is the most efficient method for the analysis of volatile and semivolatile compounds. Its primary objective is to achieve the desired resolution of the compounds of a mixture in the shortest possible time.

According to the classification of types of faster GC analyses, the analysis time of fast GC is in the minutes range and the usual peak width at half height ( w 1/2) is $0.2-3 \mathrm{~s}$. The definition based on the peak width (van Deursen, 2000) takes into account also the aspect of separation. Speeding up the GC analysis provides unquestionable benefits compared to conventional GC, such as higher laboratory throughput, reduced GC operating costs, and better analytical precision leading to higher replicability of the analyses. Reduction of the column inner diameter (I.D.) leads to a shorter analysis time at constant resolution. By reducing the I.D., a higher efficiency per length is achieved. The decrease of the column diameter results in a proportionally decreased value of the minimum plate height (Cramers, 1999; Cramers, 1999). Therefore, the column length can be decreased by the same factor in order to yield the same plate number in a shorter time. When the I.D. is reduced, the optimal average linear velocity is also higher. The penalty to be paid is a much lower sample capacity that may sooner affect the column performance deterioration represented by the peak broadening, tailing, adsorption, reactivity and even ghost peaks (Hajšlová, 2003; Domotorová, 2006).

The main aims of this work were to develop and optimise the MSPD sample preparation procedure in connection with fast GC analysis employing a selective mass spectrometric detector. Several parameters of the sample preparation method were optimised for the most common raw plant material for baby food production - apple. The objectives of this work were to reach satisfactory recoveries, i.e. limits of quantification (LOQs) lower than $10 \mu \mathrm{g} \cdot \mathrm{kg}^{-1}$. EU MRLs are in the range of $0.01-10 \mathrm{mg} \cdot \mathrm{kg}^{-1}$ (Villaverde, 2016).

\section{Experimental}

\section{Chemicals}

Twenty pesticides of the purity $>95 \%$ belonging to different chemical classes were obtained from various sources. Stock solution of pesticides was prepared in toluene (Suprasolv, Merck, Darmstad, Germany) with the approximate concentration of $0.5 \mathrm{mg} / \mathrm{ml}$, it was stored at $-18{ }^{\circ} \mathrm{C}$ and diluted in toluene to get the working standards. These standards were weighted on a Sartorius Analytic MC1 scales (Sartorius, Götingen, Germany).

The stock solution of pesticides was diluted with acetone (Suprasolv, Merck, Darmstad, Germany) to get the appropriate pesticide standard solutions for the preparation of spiked samples and matrix matched standards. Ethyl acetate and dichloromethane were of gas chromatography grade $(\mathrm{Su}-$ prasolv, Merck, Darmstad, Germany). Magnesium sulphate (anhydrous powder) was purchased from Lachema (Neratovice, Czech Republic). The sorbent used was Florisil (60-100 mesh) from Rotichrom, Roth, Karlsruhe, Germany. Apples were mixed with a blender Braun MX 2050 (Kronberg, Germany).

\section{Sample preparation}

Apples with peel were homogenously mixed with a blender. The apples used for validation purposes were checked by GC-MS for pesticide residues and none of the selected ions were found at the corresponding retention time of the selected pesticides.

\section{$M S P D$}

In a glass mortar, $5 \mathrm{~g}$ of a sample and $8 \mathrm{~g}$ of Florisil were blended, then transferred into a $25 \mathrm{~cm} \times 15 \mathrm{~mm}$ I.D. glass column plugged with glass wool and containing a layer of $2.5 \mathrm{~g}$ of anhydrous magnesium sulphate. The column head was covered with a second $2 \mathrm{~mm}$ layer of anhydrous magnesium sulphate. The column was eluted with $60 \mathrm{ml}$ of ethyl acetate by gravitational flow. The eluate was collected, concentrated to dryness using a rotary vacuum evaporator and the dry rest was dissolved in $1 \mathrm{ml}$ of toluene.

\section{Chromatographic instrumentation and conditions}

The narrow bore capillary column CP-Sil 8 CB (Varian, Middelburg, The Netherlands) with a $5 \%$ diphenyl and $95 \%$ dimethylsiloxane stationary phase, $15 \mathrm{~m} \times 0.15 \mathrm{~mm}$ I.D. $\times 0.15 \mu \mathrm{m}$ was used. It was connected to a non-polar deactivated pre-column (1m long, 0.32 mm I.D., Supelco, Bellefonte, USA) via a press-fit connector 0.32-0.2 (0.1) mm (Agilent Technologies, Switzerland) and sealed with a polyimide resin (Supelco, Bellefonte, USA).

\section{GC-MSD}

GC-MS measurements were performed in an Agilent 6890N GC coupled to 5973 MSD (Agilent Technologies, Little Falls, DE, USA) equipped with PTV and an autoinjector Agilent 7683. MS with the electron impact ionization (EI) mode $(70 \mathrm{eV})$ was operated in the SIM mode; for each pesticide, two specific ions were selected (Table 1) and sorted 
into groups; the applied dwell time was $10 \mathrm{~ms}$. PTV was operated in the cold splitless mode. The injection volume was $2 \mu \mathrm{l}$. Helium with the purity of 5.0 (Linde Technoplyn, Bratislava, Slovak Republic) was used as the carrier gas.

Tab. 1. List of pesticides, monitored ions by GC-MS in the SIM mode.

\begin{tabular}{lc}
\hline Pesticide & $\begin{array}{c}\text { Monitored ions in SIM } \\
\text { mode, Target ion }\end{array}$ \\
\hline Dimethoate & $\mathbf{8 7}, 125$ \\
Terbuthylazine & $\mathbf{2 1 4}, 229$ \\
Diazinon & $\mathbf{2 7 6 , 3 0 4}$ \\
Pyrimethanil & $\mathbf{1 9 8}, 199$ \\
Chlorpyrifos-methyl & $\mathbf{2 8 6 , 2 8 8}$ \\
Fenitrothion & $260, \mathbf{2 7 7}$ \\
Chlorpyrifos & $286, \mathbf{3 1 4}$ \\
Cyprodinyl & $224, \mathbf{2 2 5}$ \\
Penconazole & $\mathbf{2 4 8 , 2 5 0}$ \\
Methidathion & $\mathbf{1 4 5}, 302$ \\
Kresoxim-methyl & $\mathbf{1 3 1}, 132$ \\
Myclobutanil & $\mathbf{1 7 9 ,} 245$ \\
Tebuconazole & $\mathbf{2 5 0 , 2 5 2}$ \\
Phosalone & $\mathbf{1 8 2 , 3 6 7}$ \\
Bitertanol 1 & $\mathbf{1 6 8 , \mathbf { 1 7 0 }}$ \\
Bitertanol 2 & \\
Cypermethrin 1 & $163, \mathbf{1 8 1}$ \\
Cypermethrin 2 & \\
Cypermethrin 3 & \\
Etofenprox & $\mathbf{1 6 3 , 3 7 6}$ \\
\hline
\end{tabular}

Other conditions in a $0.15 \mathrm{~mm}$ I.D. column: constant pressure of $363.5 \mathrm{kPa}$ was used until the elution of the last analyte (etofenprox, at $7.90 \mathrm{~min}$ ), additional pressure ramp $(1000 \mathrm{kPa} / \mathrm{min}, 685 \mathrm{kPa})$ was used to speed-up the elution of higher boiling matrix co-extractives. Chromatographic separation was performed under a temperature program: $130{ }^{\circ} \mathrm{C}(1.13 \mathrm{~min}), 27.25{ }^{\circ} \mathrm{C} / \mathrm{min}, 290{ }^{\circ} \mathrm{C}(8 \mathrm{~min})$. PTV conditions: temperature program: $150{ }^{\circ} \mathrm{C}$, $400{ }^{\circ} \mathrm{C} / \mathrm{min}, 300^{\circ} \mathrm{C}(2 \mathrm{~min}), 400^{\circ} \mathrm{C} / \mathrm{min}, 350{ }^{\circ} \mathrm{C}$ (5 min); split vent open time of $1.13 \mathrm{~min}$; flow rate of $160 \mathrm{ml} / \mathrm{min}$.

\section{Results and discussion}

A critical aspect of pesticide residues analysis is the purification, which is required to isolate the residues from matrix components, to reduce matrix effects, and to ensure sufficient column sample capacity and satisfactory long-term chromatographic system performance during the analysis of a range of samples. Although crude extract injection into the chromatographic system can be found in several publications, clean-up procedures are still necessary. Among them, SPE and GPC are the most widely applied food analysis methods; SPE (Leandro, 2005; Anastassiades, 2003; Schenck, 2000) is still the most effective clean-up method. Differences in the validation parameters related to various sample preparation methods published in the last years are not significant. Differences in the methods as well as the demands on chemicals, material, and the time were considered. From this point of view, the most time-consuming methods are the Schenck's method (Schenck, 2000) and MSPD. It is necessary to carry out evaporation under $\mathrm{N}_{2}$ and the cleaning step in an SPE column. The original QuEChERS method (Anastassiades, 2003) does not involve the solvent exchange step and therefore it is the fastest and least laborious method. In terms of time, space, and financial demands, laboriousness, material, and solvent consumption, the following order was established: QuEChERS, modified QuEChERS, MSPD and the Schenck's method (Hercegová, 2006).

The increased urgency to reduce solvent consumption and manual labour led to commercial introduction of several alternative extraction approaches. SFE is used sporadically for the extraction of pesticide residues in laboratories due to the high instrumentation cost and the demand for optimisation of a high number of parameters for every matrix. The highest advantage of SFE in food analysis is the possibility of high extraction selectivity, the obtained extract is relatively pure and pre-concentrated (Eller, 1997).

To develop an MSPD sample preparation method in apples as non-fatty food representatives, the fast GC-MS configuration was applied. Apple sample free of pesticides was used for the preparation of a matrix matched standard prepared in blank extracts. The GC-MS shows that blanks were free of the selected pesticides. The first two solvents of different polarity, ethyl acetate and dichloromethane, were tested as eluents $(80 \mathrm{~mL})$. After eluent evaporation, the final volume used for the residues reconstitution was $1 \mathrm{~mL}$ of toluene. The recoveries of pesticides in fortified apples at the level of $120 \mu \mathrm{g} \mathrm{kg}^{-1}$ ranged between $97-113 \%$ for ethyl acetate and 83-97 \% for dichloromethane. The difference in the background of chromatograms of the two solvents was not significant; therefore, ethyl acetate was used as the eluting solvent in further experiments. Then, the eluting volume was tested and the volume of $60 \mathrm{~mL}$ was considered as sufficient to reach satisfactory recoveries (95-105\%). Finally, the final volume of toluene was adjusted. Although the spiking concentration level for the final volume of $0.5 \mathrm{~mL}$ was two times lower than 
that needed for $1 \mathrm{~mL}$ to obtain peaks of the same height, the background increased moderately with the peak height. The recoveries of over $90 \%$ were found. Further reduction of the final volume led to significantly lower precision and higher background causing problems with the matrix induced enhancement effect.

To minimise the impact of the matrix effect, five injections of a blank apple sample were injected before the injections of spiked samples and matrix matched standards.

Recoveries at three spiking levels of 5, 10 and $100 \mu \mathrm{g} \cdot \mathrm{kg}^{-1}$ are presented in Table 2 . The recovery results fell within the commonly accepted range of $70-110 \%$ and $\leq 20 \%$ RSD (except for tebuconazole at $5 \mu \mathrm{g} \cdot \mathrm{kg}^{-1}$ level with RSD of $54 \%$ due to matrix interference).

Satisfactory results were obtained even without the final evaporation step; evaporation in a rotary vacuum evaporator was followed by reconstitution in $1 \mathrm{~mL}$ of toluene, to save time and simplify the overall sample preparation procedure. Moreover, the burden on chromatographic system decreases. Figure1 represents extracted chromatograms of the target ions of pesticides in apple matrix matched
Tab. 3. Limits of quantification $\left(\mu \mathrm{g} \cdot \mathrm{kg}^{-1}\right)$.

\begin{tabular}{lc}
\hline Pesticide & LOQ \\
\hline Dimethoate & 2.77 \\
Terbuthylazine & 0.25 \\
Diazinon & 0.36 \\
Pyrimethanil & 0.07 \\
Chlorpyrifos-methyl & 0.08 \\
Fenitrothion & 0.16 \\
Chlorpyrifos & 0.30 \\
Cyprodinyl & 0.65 \\
Penconazole & 0.60 \\
Methidathion & 2.76 \\
Kresoxim-methyl & 0.68 \\
Myclobutanil & 2.00 \\
Tebuconazole & 0.59 \\
Phosalone & 0.57 \\
Bitertanol 1 & 0.24 \\
Bitertanol 2 & 2.25 \\
Cypermethrin 1 & 1.42 \\
Cypermethrin 2 & 2.72 \\
Cypermethrin 3 & 5.03 \\
Etofenprox & 1.20 \\
\hline
\end{tabular}

Tab. 2. Results of the recovery (R) experiments of pesticide residues from apples at the spiking level of 5 , 10 and $100 \mu \mathrm{g} \cdot \mathrm{kg}^{-1}$, and relative standard deviations (RSD) of fortified pesticides in apples.

\begin{tabular}{|c|c|c|c|c|c|c|}
\hline \multirow{2}{*}{ Pesticide } & \multicolumn{2}{|c|}{$5 \mu \mathrm{g} \cdot \mathrm{kg}^{-1}$} & \multicolumn{2}{|c|}{$10 \mu \mathrm{g} \cdot \mathrm{kg}^{-1}$} & \multicolumn{2}{|c|}{$100 \mu \mathrm{g} \cdot \mathrm{kg}^{-1}$} \\
\hline & $\mathrm{R} \%$ & RSD \% & $\mathrm{R} \%$ & RSD \% & $\mathrm{R} \%$ & RSD \% \\
\hline Dimethoate & 85 & 5.1 & 107 & 15 & 99 & 2.5 \\
\hline Terbuthylazine & 100 & 7.3 & 99 & 1.8 & 96 & 0.9 \\
\hline Diazinon & 94 & 5.1 & 91 & 6.5 & 93 & 8.2 \\
\hline Pyrimethanil & 93 & 0.6 & 94 & 3.1 & 94 & 1.0 \\
\hline Chlorpyrifos-methyl & 94 & 0.6 & 95 & 3.9 & 93 & 4.0 \\
\hline Fenitrothion & 97 & 4.7 & 95 & 4.0 & 95 & 2.0 \\
\hline Chlorpyrifos & 91 & 1.8 & 93 & 0.9 & 93 & 2.8 \\
\hline Cyprodinyl & 92 & 2.6 & 90 & 1.2 & 94 & 0.9 \\
\hline Penconazole & 87 & 5.0 & 99 & 1.0 & 97 & 0.5 \\
\hline Methidathion & 98 & 1.5 & 106 & 1.9 & 96 & 0.7 \\
\hline Kresoxim-methyl & 99 & 8.5 & 71 & 19 & 93 & 2.4 \\
\hline Myclobutanil & 96 & 9.5 & 99 & 1.1 & 96 & 0.3 \\
\hline Tebuconazole & 80 & 54 & 92 & 0.8 & 97 & 2.5 \\
\hline Phosalone & 87 & 18 & 105 & 16 & 95 & 0.6 \\
\hline Bitertanol 1 & 96 & 1.8 & 94 & 3.3 & 95 & 0.9 \\
\hline Bitertanol 2 & 92 & 13 & 96 & 3.5 & 91 & 0.6 \\
\hline Cypermethrin 1 & 107 & 2.5 & 92 & 13 & 93 & 6.1 \\
\hline Cypermethrin 2 & 79 & 18 & 91 & 20 & 91 & 0.7 \\
\hline Cypermethrin 3 & 80 & 18 & 96 & 1.5 & 95 & 7.3 \\
\hline Etofenprox & 85 & 4.6 & 91 & 6.5 & 94 & 3.0 \\
\hline
\end{tabular}



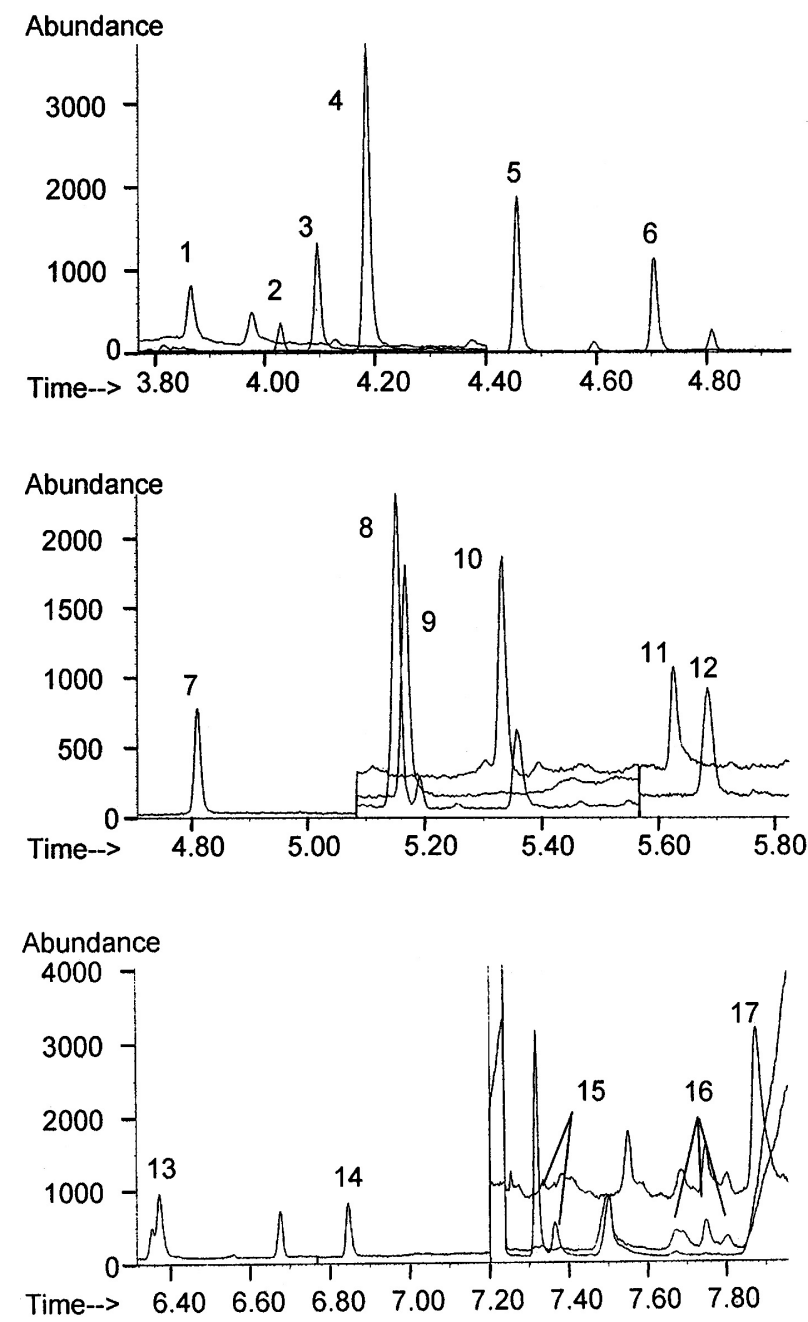

Fig. 1. Extracted chromatograms of target ions of pesticides in apple matrix matched standard solutions; concentration of pesticides

of $10 \mu \mathrm{g} \mathrm{kg}^{-1}$; 1: dimethoate, 2: terbuthylazine,

3: diazinon, 4: pyrimethanil, 5: chlorpyrifosmethyl, 6: fenitrothion, 7: chlorpyrifos,

8: cyprodinyl, 9: penconazole, 10: methidathion, 11: kresoximmethyl, 12: myclobutanil,

13: tebuconazole, 14: phosalone, 15: bitertanol, 16: cypermethrin, 17: etofenprox

standard solutions at the pesticides concentration of $10 \mu \mathrm{g} \cdot \mathrm{kg}^{-1}$ obtained by MSPD.

Linearity of the GC-MS response in the SIM mode was checked with the calibration matrix matched standards in blank extracts. Linearity of the GC-MS response was checked with matrix matched standards. The obtained coefficients of determinations, $\mathrm{R}^{2}$, in the concentration range of $5-100 \mu \mathrm{g} \cdot \mathrm{kg}^{-1}$ were 0.9980-1.00, except for cypermethrin1 (0.9593). Table 3 presents the LOQs obtained by the GC-MS analysis in the SIM mode. LOQs were determined as the concentration of a compound providing a response which relates to $\mathrm{S} / \mathrm{N}=10$.

\section{Conclusions}

Application of fast GC in combination with MSPD sample preparation for ultratrace analysis of pesticides in non-fatty food was performed. Several parameters of the MSPD procedure were optimised. The elution solvent ethyl acetate with the elution volume of $60 \mathrm{~mL}$ was selected to extract pesticides from the homogenised sample using sorbent Florisil. The final volume of $0.5 \mathrm{~mL}$ was adjusted by evaporation of the reconstituted solution under $\mathrm{N}_{2}$. Under these conditions, recoveries in the range of $97-119 \%$ were obtained at the concentration level of $120 \mu \mathrm{g} \cdot \mathrm{kg}^{-1}$. Good pesticides recoveries were achieved at the concentration levels of 5, 10 and $100 \mu \mathrm{g} \cdot \mathrm{kg}^{-1}$. The LOQs reached were between $0.07-5 \mu \mathrm{g} \cdot \mathrm{kg}^{-1}$. The pesticides content did not exceed the MRLs set by the European Commission for commodity apple. LOQs meet even the requirement on baby food; the values are lower than $5 \mu \mathrm{g}$. $\mathrm{kg}^{-1}$ (MRL set for baby food it is $10 \mu \mathrm{g} \cdot \mathrm{kg}^{-1}$ ). Good linearity $\left(\mathrm{R}^{2}\right.$ between $\left.0.9995-1\right)$ was reached in the range of $0.025-0.5 \mathrm{mg} . \mathrm{L}^{-1}$, which corresponds to $5-100 \mu \mathrm{g} \cdot \mathrm{kg}^{-1}$ in the apple sample.

\section{References}

Anastassiades M, Lehotay SJ, Štajnbaher D, Schenck FJ (2003) J. AOAC Int. 86: 412-431.

Blasco C, Picó Y, Mañes J, Font G (2002) J. Chromatogr. A, 947: 227-235.

Commission Directive 2003/13/EC of 10 February 2003 amending Directive 96/5/EC on processed cereal-based foods and baby foods for infants and young children, Official Journal, L41/33.

Cramers CA, Leclercq PA (1999) J. Chromatogr. A 842: $3-13$.

Cramers CA, Janssen H-G, van Deursen MM, Leclercq PA (1999) J. Chromatogr. A 856: 315-329.

van Deursen MM, Beens J, Janssen HG, Leclerq PA, Cramers CA (2000) J. Chromatogr. A 878: 205-213.

Dömötörová M, Matisová E, Hrouzková S, Hercegová A (2005) Chem. Anal. (Warsaw) 50: 365-375.

Dömötörová M, Kirchner M, Matisová E, de Zeeuw Jaap (2006) J. Sep. Sci. 29: 1051-1063.

Eller KI, Lehotay SJ (1997) Analyst 122: 429-443.

Ferrer C, Martínez-Bueno MJ, Lozano A, Fernádez-Alba AR (2011) Talanta 83: 1552-1561.

Fernandes VC, Domingues VF, Mateus N, Delerue-Matos C (2011) Journal of Chromatographic Science, Vol. 49: 715-730.

Hajšlová J, Zrostlíková J (2003) J. Chromatogr. A 1000: 181-197.

Hercegová A, Dömötörová M, Kružlicová D, Matisová E (2006) J. Sep. Sci. 29: 1102-1109.

Hercegová A, Dömötörová M, Matisová E, Kirchner M, Otrekal R, Stefuca V (2005) J. Chromatogr. A 1084: $46-53$.

Kirchner M, Matisová E, Dömötörová M, de Zeeuw J (2004) J. Chromatogr. A 1055: 159-168. 
Kirchner M, Matisová E, Otrekal R, Hercegová A, de Zeeuw J (2005) J. Chromatogr. A 1084: 63-70.

Kristenson EM, Haverkate EGJ. Slooten CJ, Ramos LR, Vreuls JJ, Brinkman UATh (2001) J. Chromatogr. A, 917: 277-286.

Leandro CC, Fussell RJ, Keely BJ (2005) J. Chromatogr. A, 1085: 207-2012.

Matisová E, Dömötörová M (2003) J. Chromatogr. A 1000: 199-221.

Navarro M, Picó Y, Marín R, Mañes J (2002) J. Chromatogr. 968: 201-209.

Schenck J, Lehotay SJ, Vega V (2002) J. Sep. Sci. 25 883-890.
Schenck FJ, Lehotay SJ (2000) J. Chromatogr. A, 868: 51-61.

The Applicant Guide: Maximum Residue Levels, available at http://www.pesticides.gov.uk/au_environment. asp?id=1251, The Pesticides Safety Directorate, York, United Kingdom.

Viana E, Moltó JC, Font G (1996) J. Chromatogr. A, 754: 437-478.

Villaverde JJ, Sevilla-Morán B, López-Goti C, AlonsoPrados JL, Sandín-España P (2016) Trends in Analytical Chemistry 80: 568-580. 